\title{
Sex and degree of severity influence the prognostic impact of anemia in primary myelofibrosis: analysis based on 1109 consecutive patients
}

\author{
Maura Nicolosi ${ }^{1} \cdot$ Mythri Mudireddy ${ }^{1} \cdot$ Terra L. Lasho $^{1} \cdot$ Curtis A. Hanson ${ }^{2} \cdot$ Rhett P. Ketterling $^{3} \cdot$ Naseema Gangat $^{1}$. \\ Animesh Pardanani ${ }^{1} \cdot$ Ayalew Tefferi $^{1}$
}

Received: 12 November 2017 / Revised: 16 December 2017 / Accepted: 8 January 2018 / Published online: 30 January 2018

(c) The Author(s) 2018. This article is published with open access

Anemia is one of the major risk factors for survival in primary myelofibrosis (PMF). Current prognostic models in PMF, including the International Prognostic Scoring System (IPSS) [1], dynamic IPSS (DIPSS) [2] and DIPSS-plus [3], all list hemoglobin level $(\mathrm{Hb})$ of $<10 \mathrm{~g} / \mathrm{dl}$ as one of their risk variables. However, the $10 \mathrm{~g} / \mathrm{dl} \mathrm{Hb}$ threshold used in these prognostic models overlooks the significant difference in $\mathrm{Hb}$ levels between men and women, and, also assumes similar prognostic weight between moderate and severe anemia; in regards to the latter, for example, red cell transfusion need confers an additional point of prognostic adversity in DIPSS-plus, which is independent of and in addition to what is accounted for a hemoglobin level of $<10$ $\mathrm{g} / \mathrm{dl}$ [3]. The "dose-dependent" prognostic effect of anemia, and the effect of sex on the selection of prognostically relevant $\mathrm{Hb}$ thresholds, has previously been recognized in myelodysplastic syndromes (MDS) [4]. In the current study, we examined the severity-stratified and sex-specific prognostic contribution of anemia in PMF, in the context of other relevant clinical, cytogenetic and molecular risk factors.

The current study was approved by the Mayo Clinic institutional review board and consent from research studies

Electronic supplementary materialThe online version of this article (https://doi.org/10.1038/s41375-018-0028-x) contains supplementary material, which is available to authorized users.

$\triangle$ Ayalew Tefferi

tefferi.ayalew@mayo.edu

1 Division of Hematology, Department of Internal and Laboratory Medicine, Mayo Clinic, Rochester, MN, USA

2 Division of Hematopathology, Department of Internal and Laboratory Medicine, Mayo Clinic, Rochester, MN, USA

3 Division of Laboratory Genetics and Genomics, Department of Internal and Laboratory Medicine, Mayo Clinic, Rochester, MN, USA was obtained in all subjects. Consecutive cases of PMF were recruited from institutional databases of the Mayo Clinic, Rochester, MN, USA, where the 2016 World Health Organization (WHO) criteria for PMF were retrospectively applied to confirm the diagnosis [5]. Special precaution was taken to avoid inclusion of patients with post-polycythemia vera myelofibrosis; only one woman had a hemoglobin level of $>16 \mathrm{~g} / \mathrm{dl}(16.1 \mathrm{~g} / \mathrm{dl})$ and only one man had a hemoglobin level of $>16.5(16.7 \mathrm{~g} / \mathrm{dl})$; in both instances, rereview of clinical and bone marrow morphological features were fully consistent with PMF and there was no antecedent history of PV in either. Treatment was according to conventional standards utilized at the time of diagnosis. Clinical and laboratory data, including cytogenetic information, were collected at the time of initial referral to our institution. Cytogenetic analysis and reporting was done according to the International System for Human Cytogenetic Nomenclature (ISCN) criteria [6]. The recently revised system was used for cytogenetic risk stratification (Tefferi et al. personal communication, 17 December 2017; see Table 1 footnote). Survival was calculated from time of initial referral, commensurate with time of baseline data acquisition, including cytogenetic and mutation analysis. Standard statistical methods were used to determine significance of differences among groups in the distribution of continuous or nominal variables. Overall survival data were prepared by the Kaplan-Meier method and compared by the log-rank test. Cox proportional hazard regression model was applied for multivariable analysis. $P$ value $<0.05$ was considered significant. The Stat View (SAS Institute, Cary, NC, USA) statistical package was used for all calculations. Patients were stratified according to the severity of anemia: mild$\mathrm{Hb} \geq 10 \mathrm{~g} / \mathrm{dl}$ but below sex-adjusted lower limit of normal; moderate- $\mathrm{Hb}$ between $8 \mathrm{~g} / \mathrm{dl}$ and $<10 \mathrm{~g} / \mathrm{dl}$; and severe$\mathrm{Hb}<8 \mathrm{~g} / \mathrm{dl}$ or transfusion-dependent. Reference ranges for $\mathrm{Hb}$, at our institution, were $13.5-17.5 \mathrm{~g} / \mathrm{dl}$ for men and $12.0-15.5 \mathrm{~g} / \mathrm{dl}$ for women. 
Table 1 Univariate and multivariable analysis of survival in 1109 patients with primary myelofibrosis

Overall survival

\begin{tabular}{|c|c|c|}
\hline Variables & $\begin{array}{l}\text { Univariate analysis } P \text { value (HR, } \\
95 \% \mathrm{CI})\end{array}$ & $\begin{array}{l}\text { Multivariable analysis } P \text { value (HR, } 95 \% \\
\text { CI) }\end{array}$ \\
\hline Male & $<\mathbf{0 . 0 0 0 1}(1.3,1.2-1.5)$ & \\
\hline Age $>65$ years & $<\mathbf{0 . 0 0 0 1}(2.4,2-2.7)$ & $<\mathbf{0 . 0 0 0 1}(2,1.6-2.7)$ \\
\hline Degree of anemia & $<0.0001$ & 0.0001 \\
\hline Severe anemia & $\mathbf{0 . 0 0 0 1}(3.4,2.7-4.3)$ & $\mathbf{0 . 0 0 0 1}(2.5,1.7-3.8)$ \\
\hline Moderate anemia & $\mathbf{0 . 0 0 0 1}(2.1,1.6-2.8)$ & $\mathbf{0 . 0 2}(1.7,1.1-2.8)$ \\
\hline Mild anemia & $\mathbf{0 . 0 0 9}(1.4,1.1-1.7)$ & $\mathbf{0 . 0 1}(1.7,1.1-2.5)$ \\
\hline No anemia & Reference & Reference \\
\hline Leukocytes $>25 \times 10^{9} / 1$ & $<\mathbf{0 . 0 0 0 1}(2.2,1.8-2.6)$ & $\mathbf{0 . 0 1}(1.5,1.1-2)$ \\
\hline Platelets $<100 \times 10^{9} / 1$ & $<\mathbf{0 . 0 0 0 1}(2,1.7-2.4)$ & \\
\hline Constitutional symptoms & $<\mathbf{0 . 0 0 0 1}(1.8,1.6-2)$ & $\mathbf{0 . 0 1}(1.4,1.1-1.8)$ \\
\hline Circulating blasts $\geq 1 \%$ & $<\mathbf{0 . 0 0 0 1}(1.7,1.4-2)$ & $\mathbf{0 . 0 0 8}(1.4,1.1-1.8)$ \\
\hline $\begin{array}{l}\text { Driver mutational } \\
\text { status (type 1/like } C A L R \\
\text { reference) }\end{array}$ & $<0.0001$ & $<0.0001$ \\
\hline$J A K 2$ & $0.0001(2.6,2-3.5)$ & $0.0001(2.5,1.8-3.6)$ \\
\hline Type 2/like CALR & $\mathbf{0 . 0 0 1}(2.5,1.4-4.5)$ & $\mathbf{0 . 0 2}(2.2,1.1-4.3)$ \\
\hline$M P L$ & $\mathbf{0 . 0 1}(1.8,1.1-3)$ & $\mathbf{0 . 0 0 0 3}(2.7,1.6-4.8)$ \\
\hline Triple negative & $\mathbf{0 . 0 0 0 1}(2.4,1.6-3.6)$ & $0.0008(2.2,1.4-3.4)$ \\
\hline Type 1/like CALR absent & $<\mathbf{0 . 0 0 0 1}(2.5,1.9-3.4)$ & $<\mathbf{0 . 0 0 0 1}(2.5-1.7-3.5)$ \\
\hline ASXL1-mutated & $<\mathbf{0 . 0 0 0 1}(2,1.6-2.5)$ & $<\mathbf{0 . 0 0 0 1}(1.8,1.4-2.3)$ \\
\hline SRSF2-mutated & $<\mathbf{0 . 0 0 0 1}(2,1.5-2.6)$ & $\mathbf{0 . 0 0 1}(1.7,1.2-2.3)$ \\
\hline DIPSS & $<0.0001$ & \\
\hline High & $\mathbf{0 . 0 0 0 1}(10,7.3-14)$ & \\
\hline Intermediate 2 & $\mathbf{0 . 0 0 0 1}(6,4.6-8.2)$ & \\
\hline Intermediate-1 & $\mathbf{0 . 0 0 0 1}(2.7,2.0-3.6)$ & \\
\hline Low & Reference & \\
\hline DIPSS-plus & $<0.0001$ & \\
\hline High & $\mathbf{0 . 0 0 0 1}(10,7.2-13.8)$ & \\
\hline Intermediate 2 & $\mathbf{0 . 0 0 0 1}(4.7,3.3-6.3)$ & \\
\hline Intermediate-1 & $\mathbf{0 . 0 0 0 1}(2,1.4-2.9)$ & \\
\hline Low & Reference & \\
\hline Revised cytogenetic risk ${ }^{\mathrm{a}}$ & $<0.0001$ & $<0.0001$ \\
\hline VHR & $\mathbf{0 . 0 0 0 1}(3.8,2.9-4.9)$ & $0.0001(3.6,2.3-5.8)$ \\
\hline Unfavorable & $\mathbf{0 . 0 0 0 1}(1.6,1.4-2)$ & $\mathbf{0 . 0 0 0 1}(2.4,1.8-3.3)$ \\
\hline Favorable & Reference & Reference \\
\hline
\end{tabular}

The values in bold indicate a significant $P$ value $(<0.05)$

${ }^{a}$ Revised cytogenetic risk stratification: "very high risk (VHR)"- - single/multiple abnormalities of $-7, \mathrm{i}(17 \mathrm{q})$, inv(3)/3q21, 12p-/12p11.2, 11q $-/ 11 \mathrm{q} 23,+21$, or other autosomal trisomies, not including $+8 /+9$; "favorable"-normal karyotype or sole abnormalities of $13 \mathrm{q}-,+9,20 \mathrm{q}-$, chromosome 1 translocation/duplication or sex chromosome abnormality including -Y; "unfavorable"-all other abnormalities (Tefferi et al. personal communication, 05 November 2017)

A total of 1109 consecutive patients with PMF were considered (median age 65 years; 63\% men) (Supplementary table 1). DIPSS risk distribution was $11 \%$ high, $43 \%$ intermediate-2, 34\% intermediate- 1 and $12 \%$ low. Among informative cases, karyotype was "very high risk" in 7\%, unfavorable in $19 \%$ and favorable in $74 \%$; driver mutation distribution was 66\% JAK2, 16\% CALR type 1/like, 3\% CALR type 2/like, 5\% MPL and $10 \%$ triple-negative; $A S X L 1, S R S F 2$ and $U 2 A F 1$ mutation frequencies were 38 , 14 , and $16 \%$, respectively (Supplementary table 1 ). Anemia, defined as a hemoglobin level of below the lower limit of normal, adjusted for sex, was present in $950(86 \%)$ 
patients and ranged in severity from mild $(\mathrm{Hb} \geq 10 \mathrm{~g} / \mathrm{dl}$ and less than sex-adjusted lower limit of normal) in $35 \%$, to moderate $(\mathrm{Hb} \geq 8$ and $<10 \mathrm{~g} / \mathrm{dl})$ in $14 \%$, to severe $(\mathrm{Hb}<8 \mathrm{~g} /$ dl or transfusion-dependent) in $37 \%$; the prevalence of anemia in general, mild anemia and severe anemia for men vs. women were 90 vs. $78 \%, 38$ vs. $29 \%$ and 38 vs. $35 \%$, respectively $(p<0.001)$. As outlined in supplementary table 1, and not unexpectedly, patients with moderate or severe anemia displayed older age distribution, lower leukocyte and platelet counts, higher circulating blast percentage, higher prevalence of constitutional symptoms, and higher clinical and cytogenetic risk categories. Also, consistent with previous observations, U2AF1 mutations clustered with severe anemia and lower frequency of type 1/like CALR mutations [7]. On the other hand, as was evident in supplementary table 1 , there was no difference in the prevalence of marked leukocytosis or $S F 3 B 1$ or high molecular risk mutations, including ASXL1 and $S R S F 2$.

At the time of this writing, $823(74 \%)$ deaths, $82(7.4 \%)$ leukemic transformations, and 53 (4.8\%) stem cell transplants were recorded and median follow-up time for living patients was 6.1 years. In univariate analysis, all grades of anemia (i.e., mild, moderate, and severe) predicted shortened survival with HR (95\% CI) of 3.4 (2.7-4.3) for severe, 2.1 (1.6-2.8) for moderate, and 1.4 (1.1-1.7) for

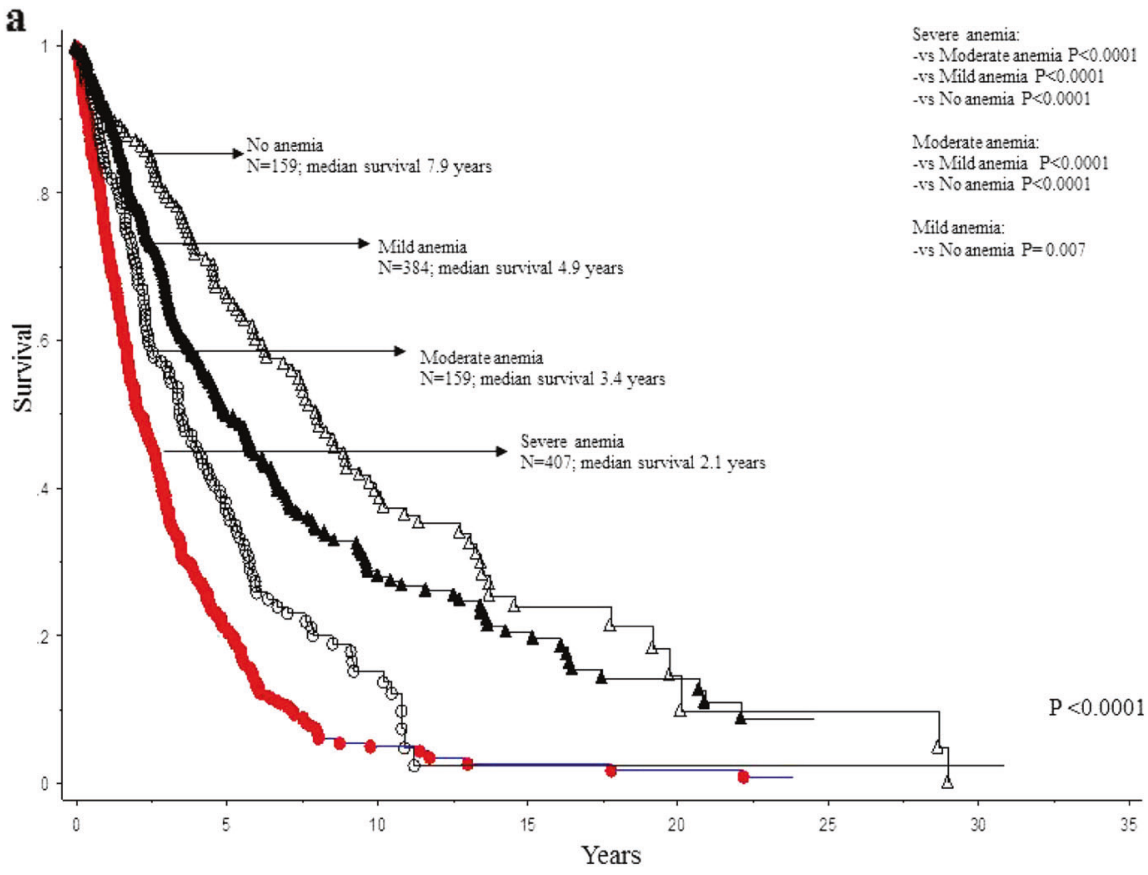

b

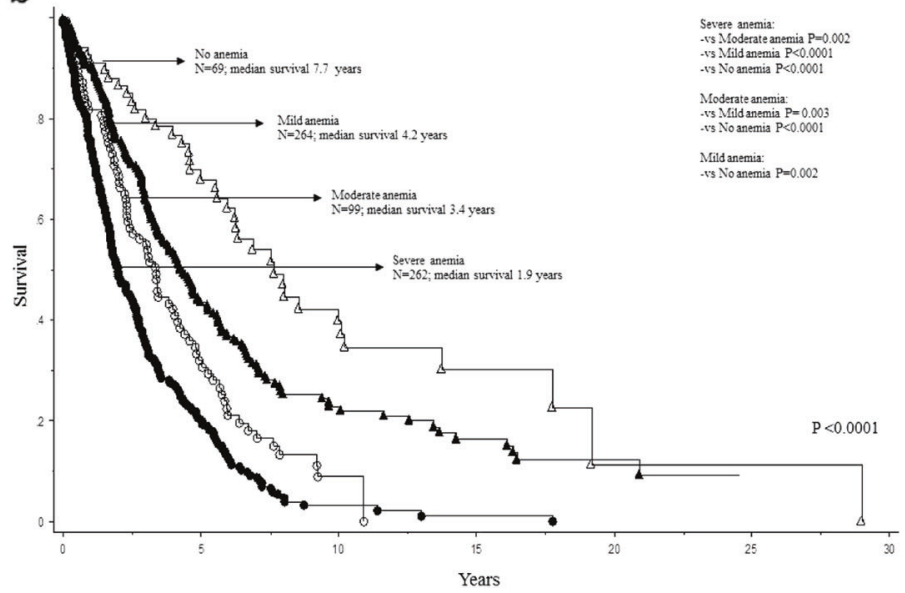

c

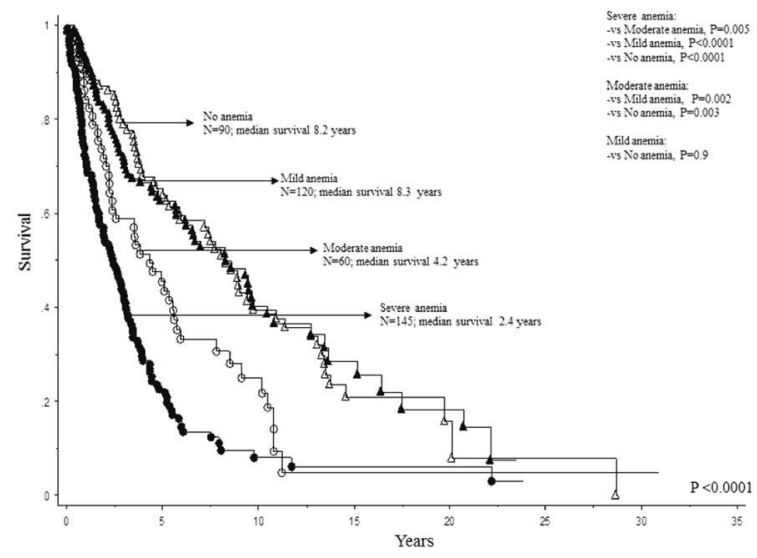

Fig. 1 a Survival data on 1109 patients with primary myelofibrosis stratified by the degree of anemia. b Survival data on 694 men with primary myelofibrosis stratified by the degree of anemia. c Survival data on 415 women with primary myelofibrosis stratified by the degree of anemia 
mild (Table 1; Fig. 1a). Prognostic relevance was sustained for all grades of anemia during multivariable analysis, with respective HR (95\% CI) of 2.5 (1.7-3.8), 1.7 (1.1-2.8) and 1.7 (1.1-2.5) for severe, moderate, and mild degrees of anemia; other variables of significance in the multivariable prognostic model included the revised cytogenetic risk stratification $(p<0.001)$, driver mutational status $\quad(p<0.001), \quad A S X L 1 \quad(p<0.001)$ and $S R S F 2$ $(p=0.001)$ mutations, and all clinical variables used in DIPSS or DIPSS-plus (Table 1). However, sex-specific analysis revealed that the prognostic contribution of mild anemia (i.e. $\mathrm{Hb} \geq 10 \mathrm{~g} / \mathrm{dl}$ but below sex-adjusted lower limit of normal) was evident only in men (HR: 1.7, 95\% CI 1.2-2.4) and not in women (HR: 1.0, 95\% CI: 0.7-1.4), whereas the impact of severe or moderate anemia were apparent in both sexes (Fig. 1b, c); severe vs no anemia HRs (95\% CI) were 3.9 (2.8-5.6) for males and 2.9 (2.1-4.0) for females, while the corresponding figures for moderate vs no anemia were $2.6(1.8-3.9)$ for males and 1.7 (1.2-2.6) for females.

In univariate analysis, severe anemia (HR: 2.8, 95\% CI: 1.3-6.0) and moderate anemia (HR: 2.7, 95\% CI: 1.2-6.2) were both associated with inferior leukemia-free survival; other variables of significance for leukemia-free survival, in univariate analysis, included platelets $<100 \times 10^{9} / 1$, circulating blasts $\geq 1 \%$, triple-negative driver mutational status, ASXL1 mutations, SRSF2 mutations, revised cytogenetic risk category, DIPSS and DIPSS-plus $(p<0.05$ in all instances). However, in multivariable analysis, prognostic relevance of degree of anemia was no longer apparent $(p=0.24)$ whereas cytogenetic risk (HR: 3.6, 95\% CI: 1.2-10.7 for very high risk karyotype and HR: $2.4,95 \% \mathrm{CI}$ : 1.2-5.0 for unfavorable karyotype), SRSF2 mutations (HR: 5.4, 95\% CI: 3.0-10.2), ASXL1 mutations (HR: 2.0, 95\% CI 1.1-3.5), platelets $<100 \times 10^{9} / 1$ (HR: $2.4,95 \%$ CI: $\left.1.3-4.4\right)$ and circulating blasts $\geq 1 \%$ (HR: 2.0 , 95\% CI: 1.1-3.5) remained significant.

In the current series of patients with PMF, anemia defined as a $\mathrm{Hb}$ level of below sex-adjusted lower limit of normal, was present in $86 \%$ of the patients. In this regard, it is important to note that there was no intential selection bias and that we did not distinguish between prefibrotic and overtaly fibrotic PMF [5]. It is conceivable that the incidence of anemia might have been lower in patients with prefibrotic PMF and in those evaluated at the time of initial diagnosis. Therefore, one should be careful in the interpretation of the results from the current study as they might not be as applicable in the setting of IPSS or prefibrotic PMF.

The current study suggests that the hemoglobin threshold level of $10 \mathrm{~g} / \mathrm{dl}$, conventionally used for prognostication in PMF, might be deficient as it fails to account for severity of anemia and effect of sex on hemoglobin levels. More specifically, we found that mild anemia, defined as a hemoglobin level of $\geq 10 \mathrm{~g} / \mathrm{dl}$, but below the sex-adjusted lower limit of normal, independently predicted shortened survival in men, but not in women (Fig. 1b, c). Also of note, severe anemia, defined as a $\mathrm{Hb}$ level of $<8 \mathrm{~g} / \mathrm{dl}$ or transfusion-dependence, was associated with a more than 1.5 -fold increase in risk of death, compared to that observed for moderate anemia, in both sexes. In this regard, it is important to note that the differential prognostic impact of anemia severity in PMF was already recognized in the context of DIPSS-plus, where adverse point allocation for anemia included two points for patients requiring red cell transfusions vs. only one point for those not requiring transfusions but displayed a hemoglobin level of $<10 \mathrm{~g} / \mathrm{dl}$ [3]. Furthermore, in a post hoc analysis of receiver operating characteristic (ROC) curve, the Hb threshold for severe anemia was determined at $8 \mathrm{~g} / \mathrm{dl}$ for women and $9 \mathrm{~g} / \mathrm{dl}$ for men. Therefore, the impact of sex on the prognostic relevance of anemia in PMF might not be restricted to only patients with mild anemia. We conclude that future prognostic models in PMF should employ sex-specific $\mathrm{Hb}$ thresholds, as is currently practiced in MDS [8], and also consider assigning prognostic scores for anemia that are proportional to its severity.

Author contributions: All authors have reviewed and approved the manuscript. CAH reviewed the pathology data. RPK reviewed the cytogenetic data. NG, AP, and AT contributed patients and assisted in the data extraction. MN and MM assisted in the data extraction, and analysis and preparation of tables and figures. TLL was in charge of molecular studies and analysis. AT developed the study concept and design, contributed patients, assisted in the data extraction, performed statistical analysis, and wrote the paper.

\section{Compliance with ethical standards}

Conflict of interest The authors declare that they have no conflict of interests.

Open Access This article is licensed under a Creative Commons Attribution-NonCommercial-NoDerivatives 4.0 International License, which permits any non-commercial use, sharing, distribution and reproduction in any medium or format, as long as you give appropriate credit to the original author(s) and the source, and provide a link to the Creative Commons license. You do not have permission under this license to share adapted material derived from this article or parts of it. The images or other third party material in this article are included in the article's Creative Commons license, unless indicated otherwise in a credit line to the material. If material is not included in the article's Creative Commons license and your intended use is not permitted by statutory regulation or exceeds the permitted use, you will need to obtain permission directly from the copyright holder. To view a copy of this license, visit http://creativecommons.org/licenses/by-nc-nd/4.0/.

\section{References}

1. Cervantes F, Dupriez B, Pereira A, Passamonti F, Reilly JT, Morra E, et al. New prognostic scoring system for primary myelofibrosis 
based on a study of the International Working Group for Myelofibrosis Research and Treatment. Blood. 2009;113: 2895-901.

2. Passamonti F, Cervantes F, Vannucchi AM, Morra E, Rumi E, Pereira A, et al. A dynamic prognostic model to predict survival in primary myelofibrosis: a study by the IWG-MRT (International Working Group for Myeloproliferative Neoplasms Research and Treatment). Blood. 2010;115:1703-8.

3. Gangat N, Caramazza D, Vaidya R, George G, Begna K, Schwager S, et al. DIPSS plus: a refined Dynamic International Prognostic Scoring System for primary myelofibrosis that incorporates prognostic information from karyotype, platelet count, and transfusion status. J Clin Oncol. 2011;29:392-7.

4. Malcovati L, Della Porta MG, Strupp C, Ambaglio I, Kuendgen A, Nachtkamp K, et al. Impact of the degree of anemia on the outcome of patients with myelodysplastic syndrome and its integration into the WHO classification-based Prognostic Scoring System (WPSS). Haematologica. 2011;96:1433-40.
5. Swerdlow SH, Campo E, Harris NL, Jaffe ES, Pileri SA, Stein H, et al. WHO classification of tumours of haematopoietic and lymphoid tissues. Lyon, France: IARC; 2017.

6. Shaffer LG, Slovak ML, Campbell LJ, (editors). ISCN 2009: An International System for Human Cytogenetic Nomenclature (2009): recommendations of the international standing committee on human cytogenetic nomenclature Basel:Karger; 2009.

7. Tefferi A, Finke CM, Lasho TL, Wassie EA, Knudson R, Ketterling RP, et al. U2AF1 mutations in primary myelofibrosis are strongly associated with anemia and thrombocytopenia despite clustering with JAK2V617F and normal karyotype. Leukemia. 2014;28:431-3.

8. Della Porta MG, Tuechler H, Malcovati L, Schanz J, Sanz G, Garcia-Manero G, et al. Validation of WHO classification-based Prognostic Scoring System (WPSS) for myelodysplastic syndromes and comparison with the revised International Prognostic Scoring System (IPSS-R). A study of the International Working Group for Prognosis in Myelodysplasia (IWG-PM). Leukemia. 2015; 29:1502-13.

\title{
Genomic profiling reveals spatial intra-tumor heterogeneity in follicular lymphoma
}

\author{
Shamzah Araf ${ }^{1,2} \cdot$ Jun Wang ${ }^{3} \cdot$ Koorosh Korfi $^{1}{ }^{1} \cdot$ Celine Pangault $^{4} \cdot$ Eleni Kotsiou ${ }^{1} \cdot$ Ana Rio-Machin $^{1}$. \\ Tahrima Rahim ${ }^{1}$ - James Heward ${ }^{1} \cdot$ Andrew Clear $\mathbb{D}^{1} \cdot$ Sameena Iqbal $^{1} \cdot$ Jeff K. Davies ${ }^{1} \cdot$ Peter Johnson ${ }^{5}$.

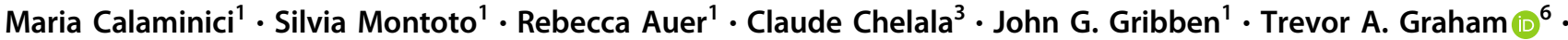 \\ Thierry Fest ${ }^{4} \cdot$ Jude Fitzgibbon ${ }^{1} \cdot$ Jessica Okosun $\mathbb{D}^{1}$
}

Received: 29 August 2017 / Revised: 17 November 2017 / Accepted: 24 November 2017 / Published online: 8 February 2018 (c) The Author(s) 2018. This article is published with open access

Follicular lymphoma (FL) is an incurable B-cell malignancy characterized by advanced stage disease and a heterogeneous clinical course, with high-risk groups including

These authors contributed equally: Shamzah Araf, Jun Wang.

Electronic supplementary materialThe online version of this article (https://doi.org/10.1038/s41375-018-0043-y) contains supplementary material, which is available to authorized users.

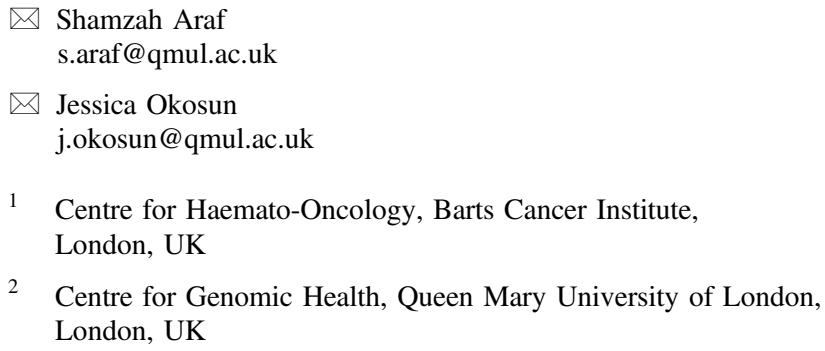

2 Centre for Genomic Health, Queen Mary University of London, London, UK

those that transform to an aggressive lymphoma, or progress early (within 2 years) following treatment. Recent sequencing studies have established the diverse genomic landscape and the temporal clonal dynamics of FL [1-7]; however, our understanding of the degree of spatial or intra-tumor heterogeneity (ITH) that exists within an individual patient is limited. In contrast, multi-site profiling in solid organ malignancies has demonstrated profound ITH impacting mechanisms of drug resistance and compromising

Centre for Molecular Oncology, Barts Cancer Institute, London, UK

4 UMR INSERM 1236, Université de Rennes, 1, EFS de Bretagne, CHU de Rennes, Rennes, France

5 Cancer Sciences Unit, Cancer Research UK Centre, Southampton, UK

6 Evolution and Cancer Laboratory, Barts Cancer Institute, London, UK 